\title{
Fluorouracil-based neoadjuvant chemoradiotherapy with or without oxaliplatin for treatment of locally advanced rectal cancer: An updated systematic review and meta-analysis
}

\author{
Yong-Jing Yang ${ }^{1, *}$, Ling $\mathrm{Cao}^{1, *}$, Zhi-Wen $\mathrm{Li}^{2}$, Ling Zhao ${ }^{1}$, Hong-Fen Wu${ }^{1}$, Dan Yue ${ }^{1}$, \\ Jin-Lei Yang ${ }^{1}$, Zhi-Rui Zhou ${ }^{3}$, Shi-Xin Liu' ${ }^{1}$ \\ ${ }^{1}$ Department of Radiation Oncology, Cancer Hospital of Jilin Province, Changchun, 130012, People's Republic of China \\ ${ }^{2}$ Department of Anesthesiology, The First Hospital Affiliated to Jilin University, Changchun, 130012, People's Republic \\ of China \\ ${ }^{3}$ Department of Radiation Oncology, Fudan University Shanghai Cancer Center, Shanghai, 200032, People's Republic of China \\ "These authors contribute equally to this work
}

Correspondence to: Shi-Xin Liu, email: liushixin1964@126.com

Zhi-Rui Zhou, email: zzr3711@163.com

Keywords: rectal neoplasms, neoadjuvant chemoradiotherapy, oxaliplatin, meta-analysis

Received: March 06, 2016

Accepted: June 03, 2016

Published: June 14, 2016

\section{ABSTRACT}

To measure the safety and efficacy of oxaliplatin (OX) application in neoadjuvant chemoradiotherapy (CRT) for locally advanced rectal cancer (LARC), EMBASE, PubMed, Cochrane Library, and Web of Science were used for a literature search. Cochrane's risk of bias tool of randomized controlled trials (RCTs) was used for quality evaluation. The statistical analyses were performed using RevMan 5.3. In addition, 95\% confidence intervals (CIs) and pooled risk ratios (RRs) were calculated. Seven RCTs were included in our meta-analysis. After adding OX to fluoropyrimidine (FU), a marginal significant improvement in disease-free survival was noted compared with FU alone ( $R R=0.89,95 \%$ CI: $0.78-1.00 ; P=0.05)$. Neoadjuvant CRT with OX significantly decreased the distant metastasis rate $(R R=0.79,95 \% \mathrm{CI}: 0.67-0.94$, $P=0.007)$. However, no improvement in the local recurrence rate $(R R=0.86,95 \% \mathrm{CI}$ : $0.68-1.08 ; P=0.19)$ was noted. In addition, neoadjuvant $C R T$ with $O X$ also significantly increased the pathologic complete response $(R R=1.24,95 \% C I: 1.02-1.51$; $P=0.03$ ). Grade 3-4 acute toxicity and grade 3-4 diarrhea was considerably higher for $\mathrm{OX} / \mathrm{FU}$ compared with FU alone. In conclusion, the use of OX on the basis of FU/ capecitabine in preoperative CRT is feasible. LARC patients are likely to benefit from CRT regimens with OX.

\section{INTRODUCTION}

Colorectal cancer ranks as the third highest malignant tumor and the third leading cause of cancer death in the United States [1]. In 2014, 71,830 men and 65,000 women were estimated to be diagnosed with colorectal cancer, and 26,270 men and 24,040 women died of locally advanced rectal cancer (LARC) [1]. Thus, this disease is a major threat to people's health [2].

At present, fluoropyrimidine (FU) (5-fluorouracil and capecitabine)-based preoperative chemoradiotherapy (CRT) represents the standard of care for the treatment of LARC. Nevertheless, FU-based preoperative CRT only provides a significant reduction in local recurrence and not the distant metastasis rate $[2,3]$. To improve the efficacy in the treatment of LARC, the drug selection for neoadjuvant concurrent chemotherapy has become a research focus in recent years [2, 4]. Oxaliplatin (OX) is a third generation, platinum drug that has been proven to be an ideal radiosensitizer in vitro and in vivo experiments [5-9] and has been widely applied in adjuvant therapy for rectal carcinoma $[10,11]$. Thus, an increasing number of investigators have focused on OX with the expectation that it will improve the efficacy of neoadjuvant chemotherapy in LARC. The safety and efficacy of OX in neoadjuvant chemoradiotherapy for LARC has been studied in a number of phase II and III clinical trials [12-22]. In these studies, high pathologic complete response (pCR) rates 
were obtained (some trials even reached up to $28 \%$ ). In addition, adverse reactions significantly increased, but most of these were tolerable during CRT. The maximum tolerated weekly dose of OX plus FU/capecitabine was 60 or $50 \mathrm{mg} / \mathrm{m}^{2}$ [12, 14-20, 23].

A debate on whether the addition of OX as a neoadjuvant modality improves the clinical outcomes for LARC is ongoing [24]. To date, seven phase III randomized controlled trials investigated the effect of $\mathrm{OX}$ in FU/capecitabine-based neoadjuvant therapy for LARC: STAR-01 in Italy [17], ACCORD12/0405 in France [18, 25], NSABP R-04 in the USA [16, 19], $\mathrm{CAO} / \mathrm{ARO} / \mathrm{AIO}-04$ in Germany [4, 20], JIAO 2015 [21] and FOWARC study [22] in China, and PETACC-6 (NCT00766155) in Europe [26, 27]. However, these studies did not reach a consistent conclusion, especially regarding whether the addition of oxaliplatin improves disease-free survival (DFS). In 2013, a meta-analysis assessed this issue [28]. However, because most included trials did not obtain long-term survival results, the metaanalysis only summarized and analyzed the indicators of short-term effects, such as pathologic complete response (pCR). In addition, no long-term follow-up outcomes, such as DFS, were reported. To further ascertain the long-term survival effect and the safety of oxaliplatin application in neoadjuvant chemoradiotherapy for LARC, we performed an updated systematic review and meta-analysis.

\section{RESULTS}

\section{Included study}

Using the search strategy as shown in appendix, we retrieved 638 records, among which 98 records were excluded as duplicates using the "find duplicates" feature of EndNote X7. The remaining 540 records were reviewed by titles and abstracts, among which 486 were excluded because they were irrelevant and did not meet the inclusion criteria. To further determine eligibility, 46 full-text articles and 2 meeting abstracts were acquired. We then excluded an additional 39 records. Specifically, 31 records were removed because patients or interventions did not meet the inclusion criteria. Six articles were removed because they are review articles. The remaining 2 articles were removed because data were not available. The meta-analysis included 7 trials, with a total of 5415 patients: STAR-01 trial [17], ACCORD12/0405 trial [18, 25], NSABP R-04 trial [16, 19], CAO/ARO/AIO-04 trial [4, 20], JIAO 2015 [21], FOWARC study [22] and PETACC-6 trial $[26,27]$. Figure 1 shows the literature screening process, and Table 1 reveals the characteristics of the included studies.

\section{Methodological quality of included studies}

This systematic review included 7 RCTs. Each included RCT was subject to quality assessment in accordance with the Handbook of Cochrane for Systematic Reviews of Interventions [29]. The baseline characteristics of patients were reported in all RCTs. All studies mentioned "random". All studies reported an adequate randomized sequence generation. Six studies reported methods of allocation concealment. All trials described the reasons of incomplete outcome data. Two abstracts did not report long-term follow-up outcomes according to their protocol currently; thus, a selective report bias may be present $[22,26]$. Figure 2 presents the quality of all evaluated trials that were included.

\section{Disease-free survival}

Disease-free survival results were reported in 4 studies, and a total of 3109 patients with rectal cancer were included in our study. The 3-year DFS rates of these studies ranged between $72.7 \%$ and $75.9 \%$ for the $\mathrm{OX} / \mathrm{FU}$ programs. For the FU only regimens, the range was $67.9 \%$ to $74.5 \%$. A marginal significant difference between patients treated with $\mathrm{OX} / \mathrm{FU}$ programs and FU only programs $(\mathrm{RR}=0.89,95 \% \mathrm{CI}: 0.78-1.00 ; P=0.05)$ was noted in the meta-analysis for DFS. Based on heterogeneity $\left(\mathrm{Chi}^{2}=4.48, P=0.21 ; I^{2}=33 \%\right)$, a fixedeffect model was adopted (Figure $3 \mathrm{~A}$ ).

\section{Local recurrence rate}

Local recurrence rates were reported in 3 studies with a total of 2399 patients with rectal cancer; all three studies were included in this study. The 3-year LR rates ranged from $2.9 \%$ to $11.2 \%$ for the $\mathrm{OX} / \mathrm{FU}$ programs. Regarding the FU only programs, the range was from $4.6 \%$ to $12.1 \%$. No significant difference was noted between the $\mathrm{OX} / \mathrm{FU}$ and $\mathrm{FU}$ alone groups $(\mathrm{RR}=0.86,95 \%$ CI: $0.68-1.08 ; P=0.19)$ in the meta-analysis for local recurrence rated. Based on heterogeneity, $\left(\mathrm{Chi}^{2}=1.40\right.$, $P=0.71 ; I^{2}=0 \%$ ), the fixed-effect model was performed (Figure 3B).

\section{Distant metastasis rate}

Three trials reported the distant metastasis rate. A total of 2040 patients were included in the meta-analysis. $\mathrm{OX} / \mathrm{FU}$ significantly decreased the distant metastasis rate compared with FU alone $(\mathrm{RR}=0.79,95 \% \mathrm{CI}$ : 0.67-0.94, $P=0.007)$. Heterogeneity was not detected $\left(\mathrm{Chi}^{2}=2.04\right.$, $\left.P=0.36 ; I^{2}=2 \%\right)$, so the fixed-effect model was applicable (Figure 3C).

\section{pCR rate}

All included trials reported the pCR rate. A total of 5415 patients were included in the meta-analysis. The range of pCR rates was $11.3 \%$ to $19.5 \%$ for the $\mathrm{OX} / \mathrm{FU}$ regimens and from $11.3 \%$ to $17.8 \%$ for the FU only programs. Significant heterogeneity was calculated $\left(\mathrm{Tau}^{2}=0.04\right.$; 
$\mathrm{Chi}^{2}=13.68, P=0.03 ; I^{2}=56 \%$ ). Thus, a pooled analysis was performed using the random-effect model. Our metaanalysis revealed that the OX/FU significantly increased the pCR rate compared with the FU only arms $(\mathrm{RR}=1.24$, 95\% CI: 1.02-1.51; $P=0.03$ ) (Figure 4A).

\section{$\mathrm{R} 0$ resection rate}

The $\mathrm{R} 0$ resection rate was reported in 6 trials with a total of 4097 patients incorporated in this meta-analysis. Significant heterogeneity was detected $\left(\mathrm{Tau}^{2}=0.00\right.$; $\mathrm{Chi}^{2}=14.37, P=0.01 ; I^{2}=65 \%$ ), so a random-effect model was adopted. Our meta-analysis revealed no significant difference in $\mathrm{R} 0$ resection rates between the two groups $(\mathrm{RR}=0.99,95 \% \mathrm{CI}: 0.96-1.03 ; P=0.68)$ (Figure 4B).

\section{CRM status}

Four studies reported circumferential rectal margin (CRM) status; the meta-analysis included a total of 2673 patients. The CRM (+) rate ranged from $4.0 \%$ to $7.7 \%$ for the $\mathrm{OX} / \mathrm{FU}$ groups and from $6.0 \%$ to $12.7 \%$ for the FU only groups. The pooled estimate using the fixed-effect model indicated no significant difference between the two programs $(\mathrm{RR}=0.76,95 \% \mathrm{CI}$ : $0.54-1.06 ; P=0.11)$ (Figure 4C).

\section{Grade 3-4 acute toxicity}

Grade 3-4 acute toxicity was reported in 6 trials; the meta-analysis included a total of 5125 patients with LARC. The rates of grade 3-4 acute toxicity ranged from $23.0 \%$ to $40.1 \%$ for the $\mathrm{OX} / \mathrm{FU}$ arms and from $8 \%$ to $29.8 \%$ for the FU only arms. As a result of substantial heterogeneity $\left(\mathrm{Tau}^{2}=0.13 ; \mathrm{Chi}^{2}=39.42, P<0.00001\right.$; $I^{2}=87 \%$ ), we adopted a random-effect model. Our meta-analysis results indicated that $\mathrm{OX} / \mathrm{FU}$ regimens significantly increased 3-4 grade acute toxicities compared with $\mathrm{FU}$ only regimens $(\mathrm{RR}=1.92,95 \% \mathrm{CI}$ : 1.40-2.64; $P<0.0001$ ) (Figure 5A).

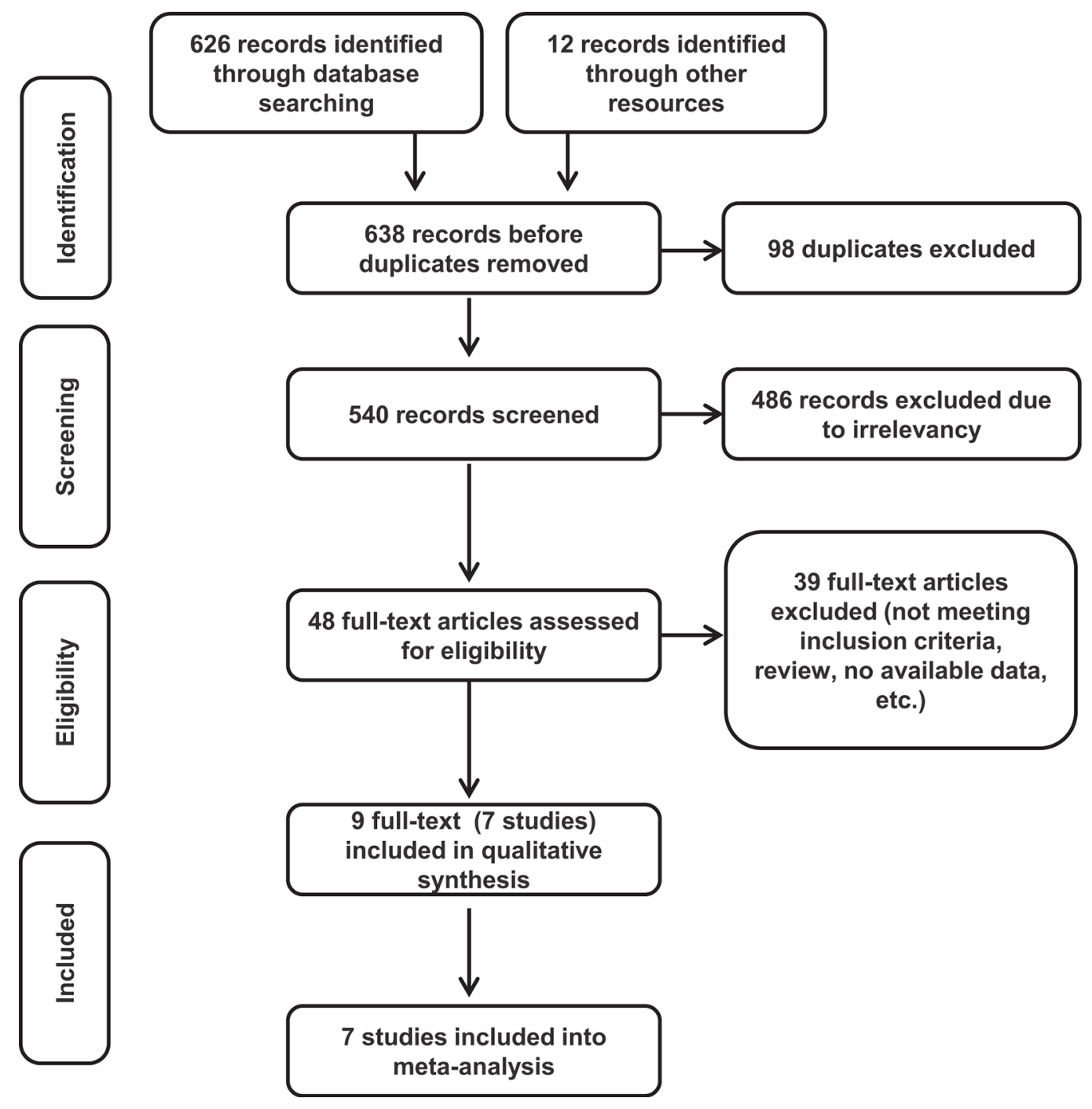

Figure 1: Flow chart of the study selection process. 
Table 1: Baseline characteristics of included trials

\begin{tabular}{|c|c|c|c|c|c|c|c|}
\hline \multirow[b]{2}{*}{ Study } & \multicolumn{2}{|c|}{ Sample Size } & \multicolumn{2}{|c|}{ Chemotherapy regimens } & \multirow[b]{2}{*}{ Radiation } & \multirow[b]{2}{*}{ Adjuvant } & \multirow[b]{2}{*}{$\begin{array}{l}\text { Follow- } \\
\text { up time }\end{array}$} \\
\hline & $\begin{array}{c}\text { Treatment } \\
\text { Group }\end{array}$ & $\begin{array}{l}\text { Control } \\
\text { Group }\end{array}$ & $\begin{array}{c}\text { Treatment } \\
\text { Group }\end{array}$ & $\begin{array}{l}\text { Control } \\
\text { Group }\end{array}$ & & & \\
\hline \multirow{2}{*}{$\begin{array}{l}\text { STAR-1, } \\
2011 \text { [17] }\end{array}$} & 368 & 379 & 5-FU + OX: & $5-\mathrm{FU}: 225 \mathrm{mg} / \mathrm{m} 2 / \mathrm{d}$ & $50.4 \mathrm{~Gy} / 28 \mathrm{f}$ & Fluorouracil-based & I \\
\hline & & & $60 \mathrm{mg} / \mathrm{m} 2 / \mathrm{w} \times 6$ & & & & \\
\hline $\begin{array}{l}\text { ACCORD, } \\
2012\end{array}$ & 299 & 299 & CAPE + OX: & CAPE: & CAPE:45Gy/25f; & Fluorouracil-based & $36.8 \mathrm{~m}$ \\
\hline$[18,25]$ & & & $50 \mathrm{mg} / \mathrm{m} 2 / \mathrm{w} \times 5$ & $800 \mathrm{mg} / \mathrm{m} 2, \mathrm{bid}, 5 \mathrm{~d} / \mathrm{w}$ & $\begin{array}{l}\text { CAP/ } \\
\text { OX:50Gy/25f }\end{array}$ & & \\
\hline $\begin{array}{l}\text { NSABP } \\
\text { R-04, } 2014\end{array}$ & $\begin{array}{l}\text { 5-FU + } \\
\text { OX:329; }\end{array}$ & 5-FU:477; & $\begin{array}{l}\text { 5-FU/CAPE + } \\
\text { OX: }\end{array}$ & 5-FU:225 mg/m2/d,5d/w or & $45 \mathrm{~Gy} / 25 \mathrm{f}+$ Boost: & Not specified & / \\
\hline$[16,19]$ & CAPE/OX:330 & CAPE:472 & $50 \mathrm{mg} / \mathrm{m} 2 / \mathrm{w} \times 5$ & CAPE: $825 \mathrm{mg} / \mathrm{m} 2, \mathrm{bid}, 5 \mathrm{~d} / \mathrm{w}$ & (5.4-10.8Gy) & & \\
\hline $\mathrm{CAO} / \mathrm{ARO} /$ & 613 & 623 & 5-FU: $250 \mathrm{mg} / \mathrm{m}^{2}$ & 5-FU:1000 mg/m2, & $50.4 \mathrm{~Gy} / 28 \mathrm{f}$ & $\begin{array}{l}\text { Control: } \\
\text { Fluorouracil } \\
\text { intravenous bolus }\end{array}$ & $50 \mathrm{~m}$ \\
\hline \multirow[t]{3}{*}{$\begin{array}{l}\text { AIO-04, } 2015 \\
{[4,20]}\end{array}$} & & & d1 -14 and $22-35$ & $\mathrm{~d} 1-5, \mathrm{~d} 29-33$ & & $\begin{array}{l}500 \mathrm{mg} / \mathrm{m} 2 \text {, day } 1-5 \\
\text { and } 29,4 \text { cycles; }\end{array}$ & \\
\hline & & & +OX: $50 \mathrm{mg} / \mathrm{m} 2$ & & & $\begin{array}{l}\text { Treatment: } \\
\mathrm{OX}+\mathrm{LV}+\mathrm{FU} \text {, day } 1\end{array}$ & \\
\hline & & & $\mathrm{d} 1,8,22,29$ & & & and 15,8 cycles & \\
\hline $\begin{array}{l}\text { PETACC-6, } \\
2014\end{array}$ & 526 & 543 & $\mathrm{CAPE}+\mathrm{OX}:$ & CAPE: & $45 \mathrm{~Gy} / 25 \mathrm{f} \pm$ Boost: & $\begin{array}{l}\text { Control: CAPE } 1000 \\
\mathrm{mg} / \mathrm{m} 2 \text {, }\end{array}$ & $31 \mathrm{~m}$ \\
\hline \multirow[t]{2}{*}[26,27]{} & & & $50 \mathrm{mg} / \mathrm{m} 2 / \mathrm{w} \times 5$ & $825 \mathrm{mg} / \mathrm{m} 2, \mathrm{bid}, 5 \mathrm{~d} / \mathrm{w}$ & (5.4Gy) & $\begin{array}{l}\text { bid,d1-15, Q3w; } \\
\text { Treatment: }\end{array}$ & \\
\hline & & & & & & $\begin{array}{l}\text { CAPE+OX: } 100 \\
\mathrm{mg} / \mathrm{m} 2 / \mathrm{d}, \mathrm{Q} 3 \mathrm{w}\end{array}$ & \\
\hline $\begin{array}{l}\text { JIAO et al, } \\
2015\end{array}$ & 103 & 103 & $\mathrm{CAPE}+\mathrm{OX}:$ & CAPE: $800 \mathrm{mg} / \mathrm{m} 2$, bid., & $50.0 \mathrm{~Gy} / 25 \mathrm{f}$ & $\begin{array}{l}\text { All patients: } 6-8 \\
\text { cycles FOLFOX }\end{array}$ & $48.7 \mathrm{~m}$ \\
\hline [21] & & & $\begin{array}{l}60 \mathrm{mg} / \mathrm{m} 2, \\
\mathrm{~d} 1,8,22,29\end{array}$ & $\mathrm{~d} 1-14, \mathrm{~d} 22-35$ & & & \\
\hline \multirow[t]{2}{*}{$\begin{array}{l}\text { FOWARC, } \\
2015 \text { [22] }\end{array}$} & 165 & 165 & mFOLFOX6 & 5-FU & $46-50.4 \mathrm{~Gy}$ & $\begin{array}{l}\text { Control: De } \\
\text { Gramont, 7cycles }\end{array}$ & / \\
\hline & & & & & $5 \mathrm{f} /$ week x 5-6w & $\begin{array}{l}\text { Treatment: } \\
\text { mFOLFOX6, } \\
\text { 7cycles }\end{array}$ & \\
\hline
\end{tabular}

CAPE: capecitabine; 5-FU, flourouracil; NSABP, National Surgical Adjuvant Breast and Bowel Project; bid: twice daily.

OX, oxaliplatin; LARCs: Locally Advanced Rectal Cancer; d:day, w:week, m:month.mFOLFOX6:5-FU,tetrahydrofolic acid, oxaliplatin.

\section{Grade 3-4 diarrhea}

Seven trials described grade 3-4 diarrhea; the metaanalysis included total of 5455 patients with LARC. The rates of the grade 3-4 diarrhea ranged between $12.0 \%$ and $18.4 \%$ for the OX/FU arms and between $3.2 \%$ and $8.0 \%$ for the FU only arms. As a result of significant heterogeneity $\left(\mathrm{Tau}^{2}=0.12 ; \mathrm{Chi}^{2}=18.50, P=0.005\right.$; $I^{2}=68 \%$ ), a random-effect model was adopted. Our meta-analysis results indicated that $\mathrm{OX} / \mathrm{FU}$ regimens significantly increased grade 3-4 diarrhea compared with FU only regimens (RR $=2.41,95 \% \mathrm{CI}$ : $1.74-3.32$; $P<0.00001$ ). (Figure 5B).

\section{Grade 3-4 radiation dermatitis}

Six studies reported grade 3-4 radiation dermatitis. The rates of grade 3-4 radiation dermatitis ranged between 
$1.4 \%$ and $5 \%$ for the OX/FU programs and from $0.4 \%$ to $3.2 \%$ for the FU alone programs. Pooled estimate adopted the fixed-effect model, which included 5249 LARC patients who were assessed for grade 3-4 radiation dermatitis. The pooled results indicated no significant difference between the two groups $(\mathrm{RR}=1.20,95 \%$ CI: 0.89-1.64; $P=0.24)$. Heterogeneity: $\mathrm{Chi}^{2}=8.09$, $P=0.15 ; I^{2}=38 \%$ (Figure 5C).

\section{Grade 3-4 hematological toxicity}

Grade 3-4 hematological toxicities were reported in 4 studies and their rates ranged between $4.8 \%$ and $5 \%$ for the $\mathrm{OX} / \mathrm{FU}$ programs and from $3.7 \%$ to $6 \%$ for the $\mathrm{FU}$ alone programs. Pooled estimate adopted the fixed-effect model. A total of 2350 patients assessed for grade 3-4 hematological events. The results of our study indicated no significant difference between the two arms $(\mathrm{RR}=1.16$, 95\% CI: 0.87-1.57; $P=0.31)$. Heterogeneity: $\mathrm{Chi}^{2}=2.00$, $P=0.57 ; I^{2}=0 \%$. (Figure 6A).

\section{Postoperative complication rate}

Postoperative complications were reported in five studies. Postoperative complication rates ranged between $24 \%$ and $47 \%$ for the $\mathrm{OX} / \mathrm{FU}$ programs and from $22 \%$ to $44 \%$ for the FU alone programs. A fixed-effect model was used for pooled analyses, which included 4818 patients

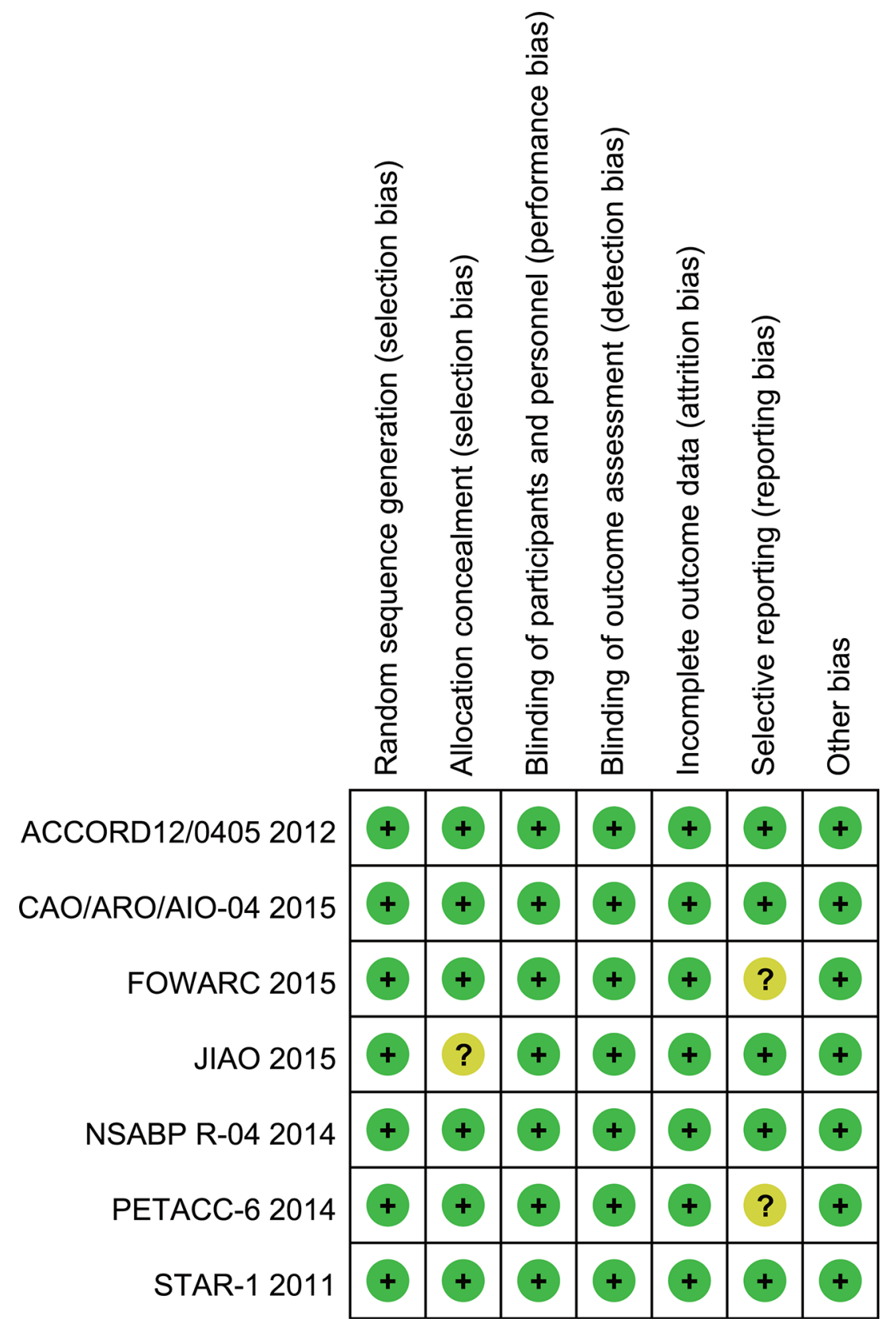

Figure 2: Risk of bias summary. A review of the authors' judgments about each risk of bias item for each included study. 
assessed for postoperative complications. No significant difference was found between the two programs $(\mathrm{RR}=1.05,95 \% \mathrm{CI}: 0.98-1.13 ; P=0.15)$ (Figure 6B).

\section{Death within 60 days}

Deaths within 60 days postoperation were reported in four studies. The fixed-effect model was used to calculate pooled estimates, which included 3724 patients. No significant difference was noted between the two programs $(\mathrm{RR}=0.83,95 \% \mathrm{CI}: 0.35-2.00 ; P=0.68)$ (Figure 6C).

\section{DISCUSSION}

The results of our meta-analysis indicated marginal significant differences in DFS between the group of FU/ capecitabine-based preoperative chemoradiotherapy and the group that employed oxaliplatin $(\mathrm{RR}=0.89,95 \% \mathrm{CI}$ : 0.78 $1.00 ; P=0.05)$. As a result, we believe that the employment of OX in preoperative chemoradiotherapy for LARC likely increases DFS rates. A larger sample size is likely needed to obtain significant differences [29, 30]. Negative DFS results were obtained from ACCORD-12 [18, 25], JIAO 2015 [21] and PETACC-6 [26], whereas a positive result was obtained from CAO/ARO/AIO-04 [20, 25]. CAO/ ARO/AIO-04 revealed that oxaliplatin groups showed a significant DFS benefit $(\mathrm{RR}=0.82,95 \% \mathrm{CI}$ : $0.68-0.97$, $P<0.05)$. Some researchers believed that the reason for the DFS benefit was that $\mathrm{CAO} / \mathrm{ARO} / \mathrm{AIO}-04$ adopted oxaliplatin-based postoperative adjuvant chemotherapy regimens $[20,25,30]$. PETACC-6, which also applied to oxaliplatin in postoperative adjuvant chemotherapy, did not achieve a similar conclusion $[26,30]$. In addition to the above reason, an increased intensity and good compliance in the adjuvant chemotherapy regimens was noted for the treatment groups compared with the control group in $\mathrm{CAO} /$ ARO/AIO-04, which may explain the difference [20, 30].

The meta-analysis results showed that the arm that employed oxaliplatin exhibited a significantly decreased distant metastasis rate $(\mathrm{RR}=0.79$, 95\%CI: $0.67-0.94$, $P=0.007)$. Furthermore, compared with FU alone,

A

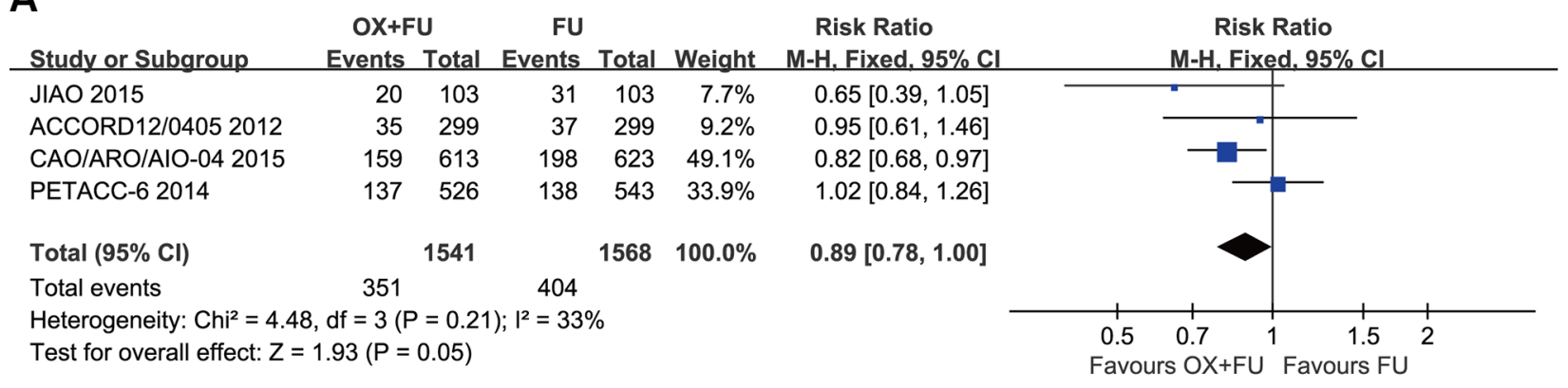

B

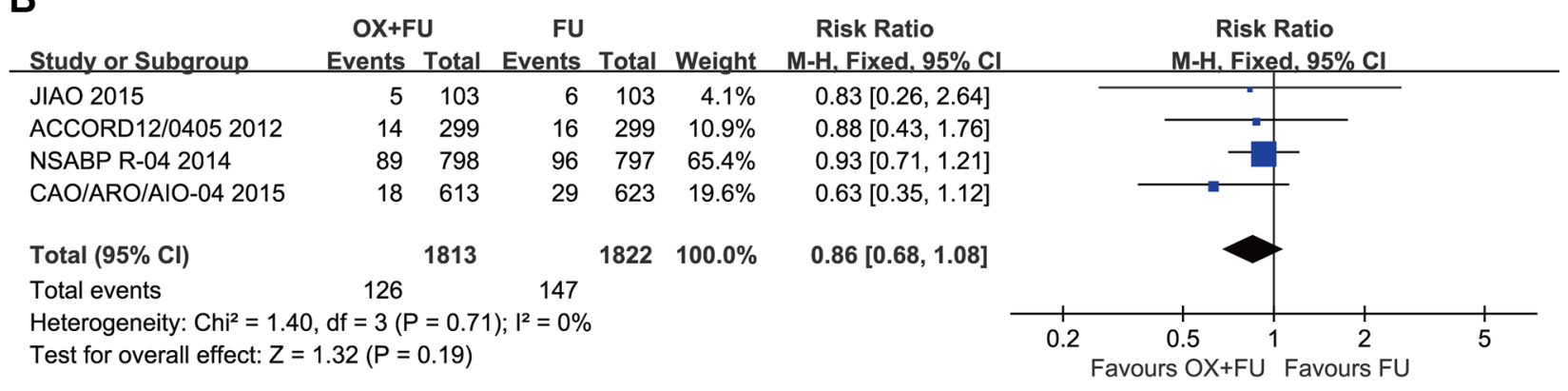

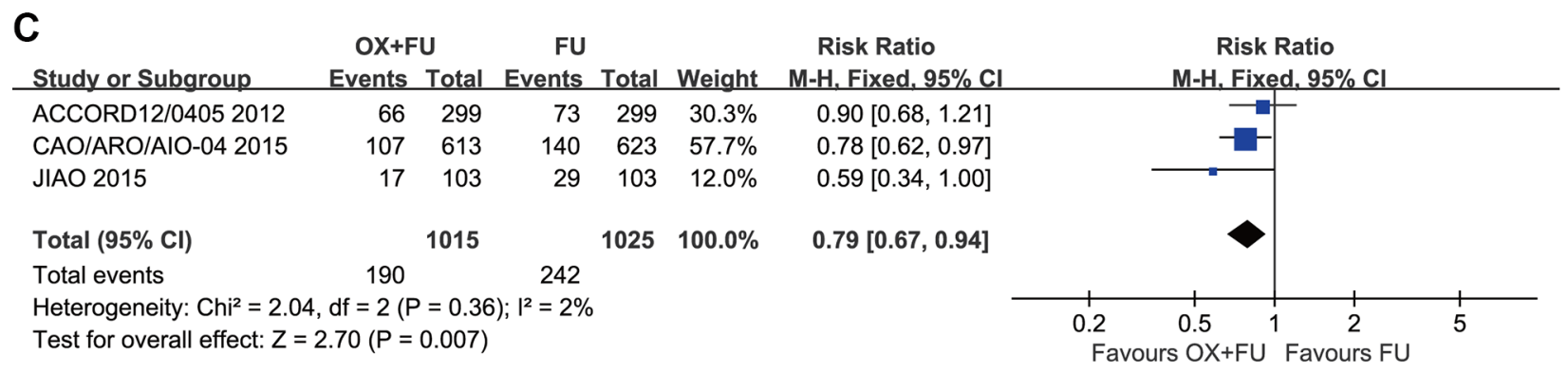

Figure 3: (A) Forest plot of risk ratio for DFS; (B) Forest plot of risk ratio for LRR; (C) Forest plot of risk ratio for DMR. 
oxaliplatin plus FU exhibited a significantly increased $\mathrm{pCR}$ rate $(\mathrm{RR}=1.24,95 \% \mathrm{CI}: 1.02-1.51 ; P=0.03)$. Five of the included trials exhibited an increase in pCR rates (the other 2 trials showed equal pCR rates). However, as a surrogate index for curative effect, the metastasis rate and pCR do not completely represent the long-term survival benefit, e.g., overall survival [31]. Additionally, the incidence of grade $3-4$ acute toxicity $(P<0.0001)$, especially that of diarrhea $(P<0.00001)$, was significantly increased in the oxaliplatin/FU groups. High heterogeneity regarding $\mathrm{pCR}, \mathrm{R} 0$ resection rate, grade $3-4$ acute toxicity and grade 3-4 diarrhea was noted in the meta-analysis primarily based on the different preoperative concurrent chemotherapy regimens and the diversity of patients in the included trials $[30,32]$. No significant differences in the local recurrence rate, $\mathrm{R} 0$ resection rate, CRM (+), grade 3-4 radiation dermatitis, grade 3-4 hematologic, postoperative complications and death within 60 days was noted. These findings suggest that the significant increase in acute adverse reactions in oxaliplatinbased chemoradiotherapy does not cause an increase in postoperative complications. Only one trial discussed late adverse reactions [20]. Late grade 3-4 adverse reactions were reported in $21 \%$ of cases in the FU alone group and in $25 \%$ of cases in the OX/FU group, and significant differences were not noted between the two arms.

Among all previous studies, only one metaanalysis addressed this topic [28]. An et al. revealed that oxaliplatin combined with FU/capecitabine significantly increased the pCR rate $(P=0.04)$ and the incidence of late grade 3-4 adverse reactions, without a significant increase in postoperative complications. This result was consistent with our meta-analyses results. However, the previous meta-analysis only presented postoperative

A

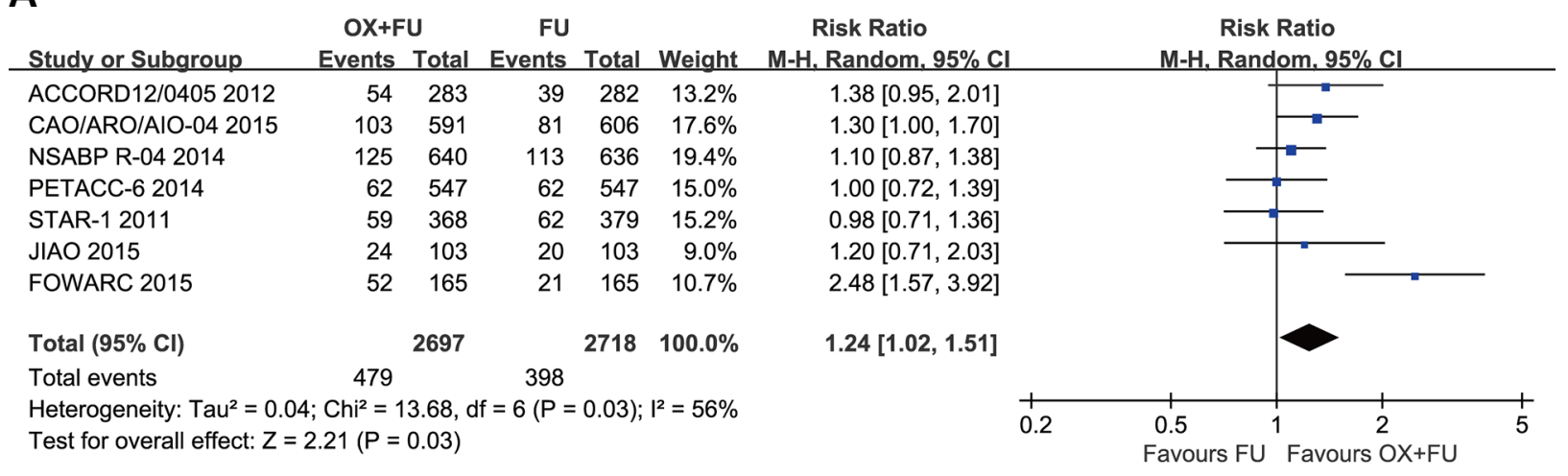

B

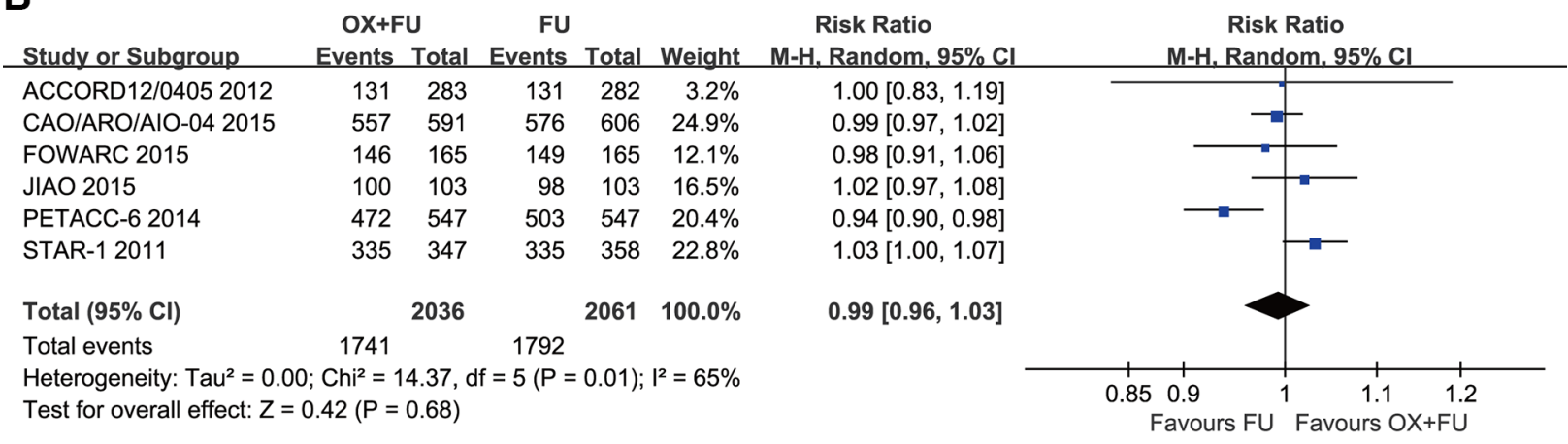

C

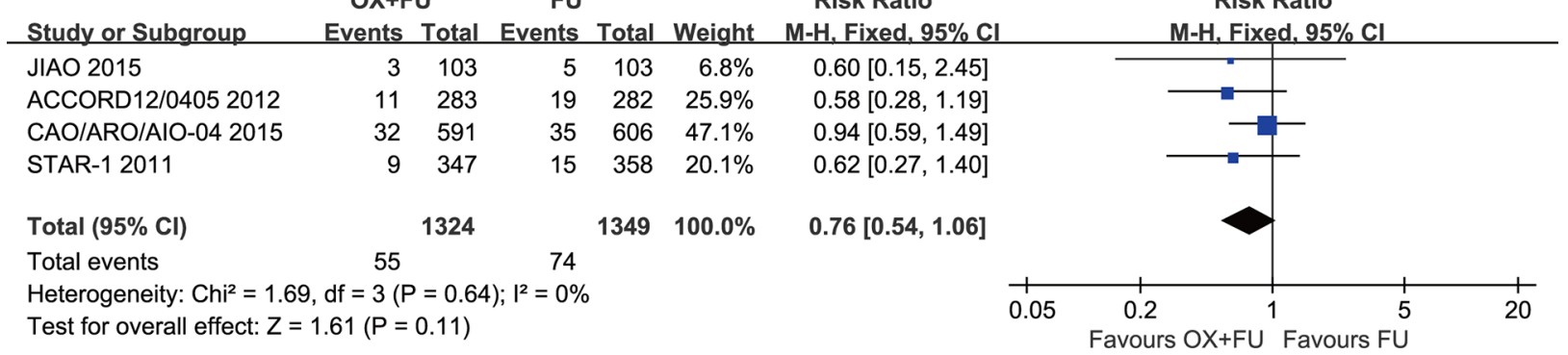

Figure 4: (A) Forest plot of risk ratio for pCR; (B) Forest plot of risk ratio for R0 resection; (C) Forest plot of risk ratio for CRM (+). 
short-term follow-up outcomes and analyzed the pCR rate, and survival outcomes from long-term follow-up were not reported. Therefore, our study further discussed the applicability of oxaliplatin in neoadjuvant therapy for the treatment of LARC with updated comparisons of prognosis and survival between the two arms.

However, some limitations in the present metaanalyses should be noted. To date, 4 of the 7 randomized clinical trials have released DFS results (ACCORD-12, CAO/ARO/AIO-04, PETACC-6 and JIAO 2015 released DFS), 4 have released LR results (JIAO 2015, ACCORD-12, NSABP R-04, CAO/ARO/AIO-04), 3 have released DMR results (JIAO 2015, ACCORD-12, CAO/ $\mathrm{ARO} / \mathrm{AIO}-04)$, and 1 has released late adverse reactions.
No RCT reported overall survival from long-term followup (median survival time greater than 5 years). Therefore, a better assessment of the efficacy and late adverse reactions of oxaliplatin in neoadjuvant therapy for LARC relies on the subsequent long-term follow-up findings of the phase III clinical trials mentioned above.

In conclusion, neoadjuvant CRT with OX improves DFS for LARC, decreases distant metastases, and significantly increases the pCR rate. However, a significant increase in toxicity was observed. Therefore, the use of oxaliplatin in neoadjuvant chemoradiotherapy for LARC is promising based on the present evidence. LARC patients are likely to benefit from treatment of CRT regimens with oxaliplatin.

A

\begin{tabular}{|c|c|c|c|c|c|}
\hline Study or Subgroup & $\begin{array}{r}\text { OX+F } \\
\text { Events }\end{array}$ & $\begin{array}{l}\text { U } \\
\text { Total }\end{array}$ & $\begin{array}{r}\text { FU } \\
\text { Events }\end{array}$ & & Weight \\
\hline ACCORD12/0405 2012 & 74 & 291 & 32 & 293 & $16.0 \%$ \\
\hline CAO/ARO/AIO-04 2015 & 140 & 606 & 127 & 624 & $19.0 \%$ \\
\hline NSABP R-04 2014 & 258 & 644 & 175 & 636 & $19.8 \%$ \\
\hline PETACC-6 2014 & 201 & 547 & 83 & 547 & $18.8 \%$ \\
\hline STAR-1 2011 & 85 & 352 & 29 & 379 & $15.7 \%$ \\
\hline JIAO 2015 & 22 & 103 & 11 & 103 & $10.8 \%$ \\
\hline Total $(95 \% \mathrm{Cl})$ & & 2543 & & 2582 & $100.0 \%$ \\
\hline Total events & 780 & & 457 & & \\
\hline
\end{tabular}

Risk Ratio

Risk Ratio , Random, 95\% Cl $2.33[1.59,3.41]$ $1.14[0.92,1.40]$

$1.46[1.24,1.70]$

$2.42[1.93,3.04]$ $3.16[2.12,4.69]$ $2.00[1.02,3.91]$

$1.92[1.40,2.64]$

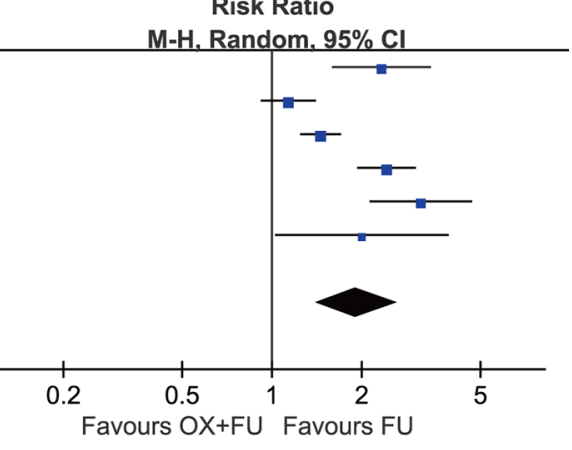

B

\begin{tabular}{|c|c|c|c|c|c|c|c|c|c|c|c|}
\hline Study or Subgroup & $\begin{array}{l}\text { OX+FL } \\
\text { Events }\end{array}$ & $\begin{array}{l}\text { U } \\
\text { Total }\end{array}$ & $\begin{array}{r}\text { FU } \\
\text { Events }\end{array}$ & Total & Weight & $\begin{array}{l}\text { Risk Ratio } \\
\text { M-H, Random, } 95 \% \mathrm{Cl}\end{array}$ & & $\begin{array}{r}\text { Ris } \\
M-H, \text { Ran }\end{array}$ & $\begin{array}{l}\text { K Ratio } \\
\text { dom. } 95 \% \mathrm{Cl}\end{array}$ & & \\
\hline ACCORD12/0405 2012 & 36 & 291 & 9 & 293 & $10.8 \%$ & $4.03[1.98,8.21]$ & & & & & \\
\hline CAO/ARO/AIO-04 2015 & 73 & 606 & 52 & 624 & $18.2 \%$ & $1.45[1.03,2.03]$ & & & & & \\
\hline NSABP R-04 2014 & 106 & 644 & 44 & 636 & $18.3 \%$ & $2.38[1.70,3.32]$ & & & & & \\
\hline PETACC-6 2014 & 101 & 547 & 31 & 547 & $17.2 \%$ & $3.26[2.22,4.79]$ & & & & & \\
\hline STAR-1 2011 & 54 & 352 & 16 & 379 & $13.9 \%$ & $3.63[2.12,6.23]$ & & & & & \\
\hline JIAO 2015 & 17 & 103 & 7 & 103 & $9.0 \%$ & $2.43[1.05,5.61]$ & & & & & \\
\hline FOWARC 2015 & 22 & 165 & 16 & 165 & $12.6 \%$ & $1.38[0.75,2.52]$ & & & & & \\
\hline Total $(95 \% \mathrm{Cl})$ & & 2708 & & 2747 & $100.0 \%$ & $2.41[1.74,3.32]$ & & & & & \\
\hline Total events & 409 & & 175 & & & & & & & & \\
\hline \multicolumn{7}{|c|}{$\begin{array}{l}\text { Heterogeneity: } \mathrm{Tau}^{2}=0.12 ; \mathrm{Chi}^{2}=18.50, \mathrm{df}=6(\mathrm{P}=0.005) ;\left.\right|^{2}=68 \% \\
\text { Test for overall effect: } Z=5.34(\mathrm{P}<0.00001)\end{array}$} & $0.1 \quad 0.2$ & 0.5 & 2 & 5 & 10 \\
\hline
\end{tabular}

\section{C}

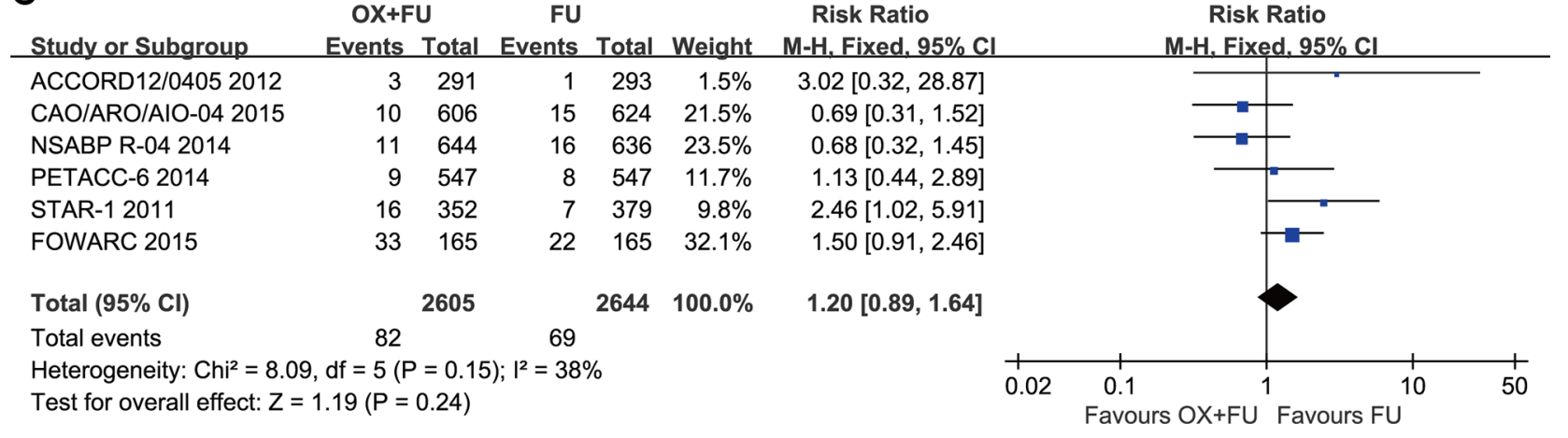

Figure 5: (A) Forest plot of risk ratio for grade 3-4 acute toxicity; (B) Forest plot of risk ratio for Grade 3-4 diarrhea; (C) Forest plot of risk ratio for grade $3-4$ radiation dermatitis. 


\section{MATERIALS AND METHODS}

\section{Inclusion and exclusion criteria}

All randomized controlled trials, published or unpublished, were eligible for this meta-analysis. All trials that evaluated the efficacy and safety of FU-based CRT with or without OX as neoadjuvant treatment for LARC were included. Non-original, quasi-randomized, non-randomized, or single-arm phase II trials were excluded.

Primary outcomes included disease free survival (DFS), distant metastasis rate (DMR) and local recurrence rate (LRR), whereas secondary outcomes included pathologic complete response (pCR), R0 resection, positive circumferential resection margin $(\mathrm{CRM}+)$, grade 3-4 acute toxicity, grade 3-4 diarrhea, grade 3-4 radiation dermatitis, grade 3-4 hematologic toxicity, death within 60 days, and postoperative complications.

\section{Literature search}

Our electronic search imposed no restrictions regarding language, publication status or publication year. Articles were obtained by searching publications from EMBASE, PubMed, the Cochrane Library and Web of Science published through December 30, 2015. Emtree or MeSH terms were used throughout the search schemes, which were adjusted appropriately in various electronic records. In addition to electronic searches for original papers, the references of involved studies were also reviewed to identify potentially eligible articles. Moreover, unpublished abstracts from the following major academic conferences were searched: ASCO (American Society of Clinical Oncology), ESSO (European Society of Surgical Oncology), ESTRO (European Society for Radiation Oncology), ASTRO (American Society for Radiation Oncology) and ESMO (European Society for Medical Oncology). We also contacted the first author or corresponding author to obtain

A

\begin{tabular}{|c|c|c|c|c|c|c|c|c|c|c|c|c|}
\hline Studv or Subgroup & $\begin{array}{r}\text { OX+F } \\
\text { Events }\end{array}$ & $\begin{array}{l}\text { U } \\
\text { Total }\end{array}$ & $\begin{array}{r}\text { FU } \\
\text { Events }\end{array}$ & Total & Weight & $\begin{array}{l}\text { Risk Ratio } \\
\text { M-H, Fixed, 95\% Cl }\end{array}$ & & & $\begin{array}{r}\text { Risl } \\
\text { M-H. Fir }\end{array}$ & $\begin{array}{l}\text { Ratio } \\
\text { ed. } 95 \% \mathrm{Cl}\end{array}$ & & \\
\hline ACCORD12/0405 2012 & 14 & 291 & 11 & 293 & $14.9 \%$ & $1.28[0.59,2.78]$ & & & & $=$ & & \\
\hline CAO/ARO/AIO-04 2015 & 32 & 606 & 36 & 624 & $48.3 \%$ & $0.92[0.58,1.45]$ & & & & & & \\
\hline JIAO 2015 & 5 & 103 & 3 & 103 & $4.1 \%$ & $1.67[0.41,6.79]$ & & & & & & \\
\hline FOWARC 2015 & 34 & 165 & 24 & 165 & $32.7 \%$ & $1.42[0.88,2.28]$ & & & & & & \\
\hline Total $(95 \% \mathrm{Cl})$ & & 1165 & & 1185 & $100.0 \%$ & $1.16[0.87,1.57]$ & & & & & & \\
\hline Total events & 85 & & 74 & & & & & & & & & \\
\hline $\begin{array}{l}\text { Heterogeneity: } \text { Chi }^{2}=2.0 \\
\text { Test for overall effect: } Z\end{array}$ & $\begin{array}{l}\mathrm{df}=3(\mathrm{P} \\
1.01(P=\end{array}$ & $\begin{array}{l}=0.57 \\
0.31)\end{array}$ & $;\left.\right|^{2}=0 \%$ & & & & 0.1 & $\begin{array}{l}0.2 \\
\text { Favol }\end{array}$ & $\begin{array}{l}0.5 \\
\mathrm{rs} \\
\mathrm{OX}+\mathrm{FL}\end{array}$ & $1 \quad 2$ & 5 & 10 \\
\hline
\end{tabular}

B

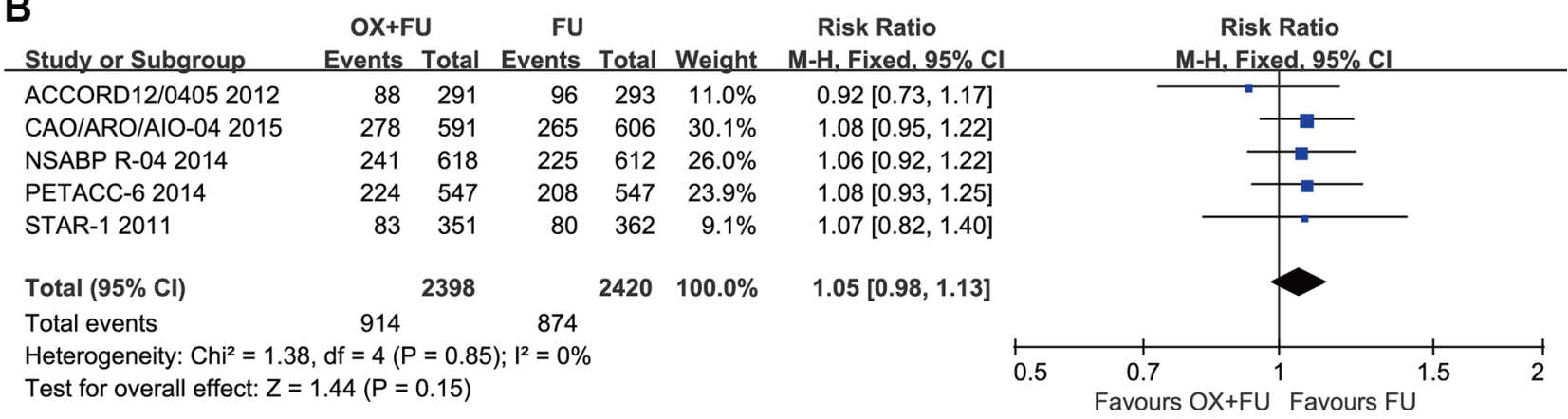

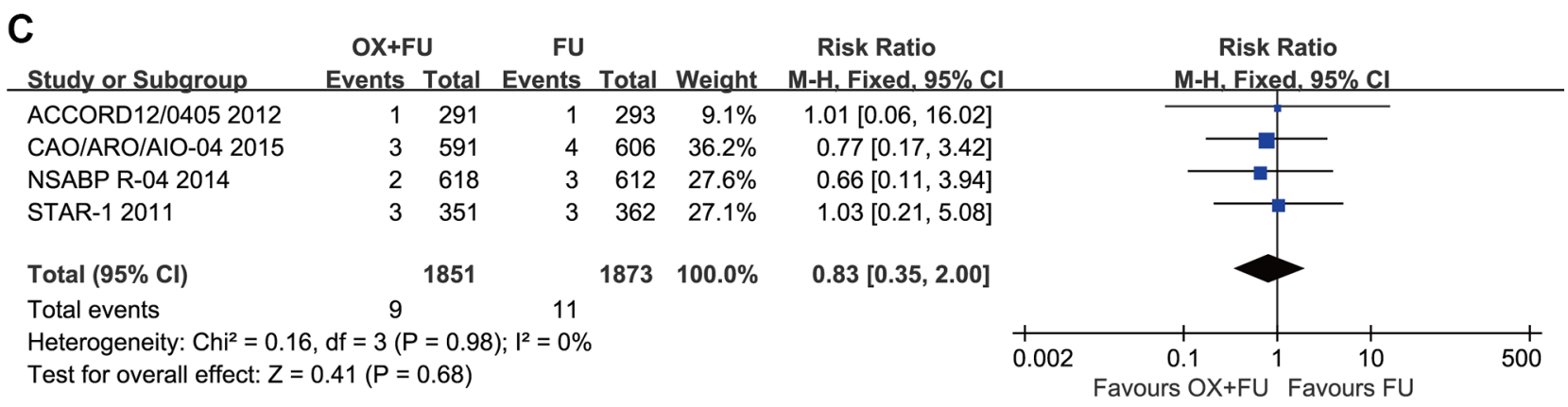

Figure 6: (A) Forest plot of risk ratio for grade 3-4 hematologic toxicity; (B) Forest plot of risk ratio for postoperative complications; (C) Forest plot of risk ratio for death within 60 days. 
information if the research results were unclear or more information was needed.

\section{Data extraction and assessment of the risk of bias}

The data extraction was performed independently by two reviewers (Ling Cao and Yong-Jing Yang). Disagreements were resolved by a third reviewer (Zhi-Rui Zhou). The following information was extracted from each included trial: participant eligibility, study design, baseline characteristics, duration of follow-up, and the number of events for all outcomes and interventions. If the results were reported in multiple publications, we extracted data from all the publications.

The quality of included studies was independently evaluated by two investigators. Assessment of the bias of the included studies was based on the Cochrane Handbook for Systematic Reviews of Interventions [32]. When needed, a third reviewer was employed to resolve disagreements. On the basis of the assessment of general sequence allocation, allocation concealment, incomplete data addressed, outcome assessment blinding (detection bias), participants and personnel blinding (performance bias), presence of biases in reports and other bias sources that may affect the validity of the study, the studies were classified as having a high, unclear or low risk of bias.

\section{Statistical analysis}

RevMan 5.3 software (The Cochrane Collaboration, UK) was used for statistical analysis. Risk ratios (RR) and $95 \%$ confidence intervals (CI) were calculated for count data. I-square and Chi-square tests were employed to assess studies-shared heterogeneity. If heterogeneity was not detected $\left(P>0.10, I^{2}<50 \%\right)$, the analysis was performed using the fixed-effect model. Otherwise, a random-effect model was used. With heterogeneity, the following three potential sources were explored: methodological, clinical and statistical. If excessive heterogeneity was noted, descriptive analysis was employed for the meta-analysis.

\section{ACKNOWLEDGMENTS}

The authors thank Eunice Xu (AME Publishing Company, Guangzhou, P.R. China) for proof reading this article.

\section{CONFLICTS OF INTEREST}

The authors declare no conflicts of interest.

\section{FINANCIAL SUPPORT}

\section{Authors' contributions}

Conception and design: Shi-Xin Liu and YongJing Yang. Collection and assembly of data: Ling Cao, Yong-Jing Yang and Zhi-Rui Zhou. Data analysis and interpretation: Ling Cao, Yong-Jing Yang and Zhi-Rui Zhou. Manuscript writing: Yong-Jing Yang, Zhi-Rui Zhou and Ling Cao. Final approval of manuscript: All authors.

\section{REFERENCES}

1. Siegel R, Desantis C, Jemal A. Colorectal cancer statistics, 2014. CA Cancer J Clin. 2014; 64:104-117.

2. Kye BH, Cho HM. Overview of radiation therapy for treating rectal cancer. Ann Coloproctol. 2014; 30:165-174.

3. Hofheinz RD, Wenz F, Post S, Matzdorff A, Laechelt S, Hartmann JT, Muller L, Link H, Moehler M, Kettner E, Fritz E, Hieber U, Lindemann HW, et al. Chemoradiotherapy with capecitabine versus fluorouracil for locally advanced rectal cancer: a randomised, multicentre, non-inferiority, phase 3 trial. Lancet Oncol. 2012; 13:579-588.

4. Rodel C, Liersch T, Becker H, Fietkau R, Hohenberger W, Hothorn T, Graeven U, Arnold D, Lang-Welzenbach M, Raab HR, Sulberg H, Wittekind C, Potapov S, et al. Preoperative chemoradiotherapy and postoperative chemotherapy with fluorouracil and oxaliplatin versus fluorouracil alone in locally advanced rectal cancer: initial results of the German CAO/ARO/AIO-04 randomised phase 3 trial. Lancet Oncol. 2012; 13:679-687.

5. Ahmad S. Platinum-DNA interactions and subsequent cellular processes controlling sensitivity to anticancer platinum complexes. Chem Biodivers. 2010; 7:543-566.

6. Burger H, Zoumaro-Djayoon A, Boersma AW, Helleman J, Berns EM, Mathijssen RH, Loos WJ, Wiemer EA. Differential transport of platinum compounds by the human organic cation transporter hOCT2 (hSLC22A2). Br J Pharmacol. 2010; 159:898-908.

7. Hermann RM, Rave-Frank M, Pradier O. Combining radiation with oxaliplatin: a review of experimental results. Cancer Radiother. 2008; 12:61-67.

8. Kjellstrom J, Kjellen E, Johnsson A. In vitro radiosensitization by oxaliplatin and 5-fluorouracil in a human colon cancer cell line. Acta Oncol. 2005; 44:687-693.

9. Magne N, Fischel JL, Formento P, Etienne MC, Dubreuil A, Marcie S, Lagrange JL, Milano G. Oxaliplatin-5fluorouracil and ionizing radiation. Importance of the sequence and influence of p53 status. Oncology. 2003; 64:280-287.

10. Bujko K, Glimelius B, Valentini V, Michalski W, Spalek M. Postoperative chemotherapy in patients with rectal cancer receiving preoperative radio(chemo)therapy: A meta-analysis of randomized trials comparing surgery $+/$ - a fluoropyrimidine and surgery + a fluoropyrimidine +/- oxaliplatin. Eur J Surg Oncol. 2015; 41:713-723.

Shi-Xin Liu. 
11. Huang XZ, Gao P, Song YX, Sun JX, Chen XW, Zhao JH, Ma B, Wang J, Wang ZN. Impact of age on efficacy of postoperative oxaliplatin-based chemotherapy in patients with rectal cancer after neoadjuvant chemoradiotherapy. Oncotarget. 2016; 7:19643-53. doi: 10.18632/ oncotarget.7544.

12. Gerard JP, Chapet O, Nemoz C, Romestaing P, Mornex F, Coquard R, Barbet N, Atlan D, Adeleine P, Freyer G. Preoperative concurrent chemoradiotherapy in locally advanced rectal cancer with high-dose radiation and oxaliplatin-containing regimen: the Lyon R0-04 phase II trial. J Clin Oncol. 2003; 21:1119-1124.

13. Rodel C, Liersch T, Hermann RM, Arnold D, Reese T, Hipp M, Furst A, Schwella N, Bieker M, Hellmich G, Ewald H, Haier J, Lordick F, et al. Multicenter phase II trial of chemoradiation with oxaliplatin for rectal cancer. J Clin Oncol. 2007; 25:110-117.

14. Machiels JP, Duck L, Honhon B, Coster B, Coche JC, Scalliet P, Humblet Y, Aydin S, Kerger J, Remouchamps V, Canon JL, Van Maele P, Gilbeau L, et al. Phase II study of preoperative oxaliplatin, capecitabine and external beam radiotherapy in patients with rectal cancer: the RadiOxCape study. Ann Oncol. 2005; 16:1898-1905.

15. Turitto G, Panelli G, Frattolillo A, Auriemma A, de Luna FS, Cione G, De Angelis CP, Muto P, Iaffaioli RV. Phase II study of neoadjuvant concurrent chemioradiotherapy with oxaliplatin-containing regimen in locally advanced rectal cancer. Frontiers in bioscience. 2006; 11:1275-1279.

16. Allegra CJ, Yothers G, O'Connell MJ, Roh MS, Lopa SH, Petrelli NJ, Beart RW, Sharif S, Wolmark N. Final results from NSABP protocol R-04: Neoadjuvant chemoradiation (RT) comparing continuous infusion (CIV) 5-FU with capecitabine (Cape) with or without oxaliplatin (Ox) in patients with stage II and III rectal cancer. J Clin Oncol. 2014; 32.

17. Aschele C, Cionini L, Lonardi S, Pinto C, Cordio S, Rosati G, Artale S, Tagliagambe A, Ambrosini G, Rosetti P, Bonetti A, Negru ME, Tronconi MC, et al. Primary tumor response to preoperative chemoradiation with or without oxaliplatin in locally advanced rectal cancer: pathologic results of the STAR-01 randomized phase III trial. J Clin Oncol. 2011; 29:2773-2780.

18. Gerard JP, Azria D, Gourgou-Bourgade S, Martel-Lafay I, Hennequin C, Etienne PL, Vendrely V, Francois E, de La Roche G, Bouche O, Mirabel X, Denis B, Mineur L, et al. Clinical outcome of the ACCORD 12/0405 PRODIGE 2 randomized trial in rectal cancer. J Clin Oncol. 2012; 30:4558-4565.

19. O'Connell MJ, Colangelo LH, Beart RW, Petrelli NJ, Allegra CJ, Sharif S, Pitot HC, Shields AF, Landry JC, Ryan DP, Parda DS, Mohiuddin M, Arora A, et al. Capecitabine and oxaliplatin in the preoperative multimodality treatment of rectal cancer: surgical end points from National Surgical Adjuvant Breast and Bowel Project trial R-04. J Clin Oncol. 2014; 32:1927-1934.
20. Rodel C, Graeven U, Fietkau R, Hohenberger W, Hothorn T, Arnold D, Hofheinz RD, Ghadimi M, Wolff HA, LangWelzenbach M, Raab HR, Wittekind C, Strobel P, et al. Oxaliplatin added to fluorouracil-based preoperative chemoradiotherapy and postoperative chemotherapy of locally advanced rectal cancer (the German CAO/ARO/ AIO-04 study): final results of the multicentre, openlabel, randomised, phase 3 trial. Lancet Oncol. 2015; 16: 979-989.

21. Jiao D, Zhang R, Gong Z, Liu F, Chen Y, Yu Q, Sun L, Duan H, Zhu S, Liu F, Wang J, Jia J. Fluorouracil-based preoperative chemoradiotherapy with or without oxaliplatin for stage II/III rectal cancer: a 3-year follow-up study. Chin J Cancer Res. 2015; 27:588-596.

22. Deng Y, Chi P, Lan P, Wang L, Cui L, Chen D, Cao J, Wei H, Peng X, Huang Z, Cai G, Zhao R, Huang Z, et al. A multicenter randomized controlled trial of mFOLFOX6 with or without radiation in neoadjuvant treatment of local advanced rectal cancer (FOWARC study): Preliminary results. J Clin Oncol. 2015; 33.

23. Chitapanarux I, Chitapanarux T, Tharavichitkul E, Mayurasakorn S, Siriwittayakorn P, Yamada S, Lorvidhaya V. A phase II study of oxaliplatin with 5-FU/folinic acid and concomitant radiotherapy as a preoperative treatment in patients with locally advanced rectal cancer. Biomed Imaging Interv J. 2011; 7:e25.

24. Fontana E, Pucci F, Camisa R, Bui S, Galdy S, Leonardi F, Negri FV, Anselmi E, Losardo PL, Roncoroni L, Dell'abate P, Crafa P, Cascinu S, et al. Long-term results of preoperative 5-fluorouracil-oxaliplatin chemoradiation therapy in locally advanced rectal cancer. Anticancer research. 2013; 33:725-730.

25. Gerard JP, Azria D, Gourgou-Bourgade S, Martel-Laffay I, Hennequin C, Etienne PL, Vendrely V, Francois E, de La Roche G, Bouche O, Mirabel X, Denis B, Mineur L, et al. Comparison of two neoadjuvant chemoradiotherapy regimens for locally advanced rectal cancer: results of the phase III trial ACCORD 12/0405-Prodige 2. J Clin Oncol. 2010; 28:1638-1644.

26. Haustermans K, Schmoll HJ, Price T, Nordlinger B, Hofheinz RD, Daisne JF, Janssens J, Schmidt P, Reinel H, Van Cutsem E. First results of the PETACC-6 randomized phase III trial in locally advanced rectal cancer. Radiotherapy and Oncology. 2014; 111:S96.

27. Schmoll HJ, Haustermans K, Price TJ, Nordlinger B, Hofheinz R, Daisne JF, Janssens J, Brenner B, Schmidt P, Reinel H, Hollerbach S, Caca K, Fauth FWB, et al. Preoperative chemoradiotherapy and postoperative chemotherapy with capecitabine and oxaliplatin versus capecitabine alone in locally advanced rectal cancer: Disease-free survival results at interim analysis. J Clin Oncol. 2014; 32.

28. An X, Lin X, Wang FH, Goodman K, Cai PQ, Kong LH, Fang YJ, Gao YH, Lin JZ, Wan DS, Pan ZZ, Ding PR. Short term results of neoadjuvant chemoradiotherapy with fluoropyrimidine alone or in combination with oxaliplatin 
in locally advanced rectal cancer: a meta analysis. Eur J Cancer. 2013; 49:843-851.

29. Moher D, Dulberg CS, Wells GA. Statistical power, sample size, and their reporting in randomized controlled trials. Jama. 1994; 272:122-124.

30. Glimelius B. Is the benefit of oxaliplatin in rectal cancer clinically relevant? Lancet Oncol. 2015; 16:883-885.
31. Baker SG, Kramer BS. A perfect correlate does not a surrogate make. BMC Med Res Methodol. 2003; 3:16.

32. Higgins JPT, Green S. Cochrane Handbook for Systematic Reviews of Interventions Version 5.1.0 [updated March 2011]. Available from wwwcochrane-handbookorg. 2011. 